Editorial

\title{
Immune Senescence and Covid-19 Pandemic
}

Giuseppe Cocco *

Marktkgasse 10, CH-4310 Rheinfelden, Switzerland; E-Mail: praxis@cocco.ch

* Correspondence: Giuseppe Cocco; E-Mail: praxis@cocco.ch

OBM Geriatrics

2020, volume 4, issue 3

doi:10.21926/obm.geriatr.2003132
Received: September 05, 2020

Accepted: September 07, 2020

Published: September 09, 2020

\begin{abstract}
Covid-19 pandemic has been infecting a substantial portion of the world population, thereby revealing quality deficits in health care in the majority of the countries around the globe. Severe illness and mortality from Covid-19 infection are present predominantly in minorities; especially they are more frequent in geriatric patients. Unfortunately, our knowledge is limited about what accounts for the variability in immune response from one person to another. This question is far from being merely academic, and finding its answer assumes critical importance for the future of global health.
\end{abstract}

\section{Keywords}

Covid-19; immune senescence; elderly; ACE2; hypertension

Risk factors, such as smoking, physical inactivity, obesity, and inappropriate eating habits, are significantly influenced by the environment in which people live. Social factors, especially in minority populations, also contribute to a disproportionately high rate of chronic illness and delays in getting health care [1]. In some countries, especially in low-income and education minorities, these factors could explain the high frequency and virulence of Covid-19 infection. Climate changes could put an additional one billion people at risk of tropical vector-borne diseases, which are emerging with increasing frequency and have the potential for causing pandemic diseases [1].

However, the highest mortality from Covid-19 infection is observed mostly in geriatric patients. This fact should force medical science to understand and determine global demographic changes; the world is facing. According to the United Nations projections, by 2050, there will be more than twice as many people over 65 as there are children under 5 , and the number of people older than 
65 globally will surpass the number of people in the age group of 15-24 years [2]. This global aging might pose widespread public health challenges, significantly increasing the burden of geriatric pathologies and exposing the vulnerable elderly population to infectious diseases [1].

Angiotensin-converting enzyme-2 (ACE2) is the receptor for SARS-Cov-2 virus. It has been suggested the differential levels of ACE2 in the cardiac and pulmonary tissues of younger versus geriatric patients might be partially responsible for the viral virulence observed among the patients. Indeed, the use of renin-angiotensin system blockers in patients with Covid-19 infection has been much debated, and it has been concluded that these blockers should not be withdrawn [3-5]. Unfortunately, it remains undetermined whether the Covid-19 mortality risks in geriatric patients can be interpreted by analyzing data of younger patients alone. Undoubtedly, health conditions associated with aging, especially cardiovascular diseases, cancers, metabolic and autoimmune diseases, and the treatments for these pathologies, interfere with the SARS-Cov-2 virus infection. Also, immune senescence, i.e., a progressive age-related decline of innate and adaptive immune responses, substantially and adversely affects the responses to infectious diseases and vaccines. Indeed, the Shingrix vaccine for shingles has proven very effective in people over 70, but our understanding of how to generate effective immunity in the elderly remains poor, and several studies have shown that vaccine efficacy decreases significantly with advancing age [6].

Protecting geriatric patients will be central, but even the most efficient health systems cannot properly cope with these individuals/issues. Despite decades of standardized measurements, public reporting, and control programs, the average quality performance of health care remains insufficient. Indeed, in the USA, adults receive about 55\% of recommended care for the leading causes of diseases and death [7]. These figures almost match with those in most countries. A good example is the management of arterial hypertension, a very common and treatable chronic pathology - a major contributor to morbidity and mortality. In the USA, in 2017 hypertension (HTN) accounted for 23 deaths per million population, but in Non-Caucasian patients, HTN rates were significantly higher, e.g., in Afro-Americans, 54.1 deaths per 1000,000 men and 37.8 per 100,000 women were recorded [8].

Clinicians know that good therapy requires applying the most effective treatment that increases better outcomes. This approach should be customized to the specific preferences and health needs of the individuals, detecting and diagnosing the pathologies, choosing the right treatment, ensuring adherence, checking treatment effectiveness, and adjusting appropriate therapy. Maintaining professionalism is crucial, although insufficient cornerstone of high-quality care and, in reality, quality of care is rarely about good health professionals versus bad ones. However, it is difficult to get a good quality of care without supportive protocols, tools and teamwork. To improve and streamline high-quality health care, an enduring framework for evaluating process, structures, and outcomes was propounded [9]. In recent time, policymakers emphasized three additional levers to improve the quality of health care: measurements, incentives, and social factors [10]. On the other hand, the relationship between politicians, policymakers, and physicians remains unhealthy [11, 12].

To conclude, this paper underlines the need that due to global demographic changes, the Covid-19 pandemic should force medical science to understand whether the immune system of geriatric patients is adequate to be properly treated with vaccines. 


\section{Acknowledgments}

Mrs. Jacqueline Bugmann typed the manuscript.

\section{Author Contributions}

The author did all the research work of this study.

\section{Competing Interests}

The author has declared that no competing interests exist.

\section{References}

1. Koff WC, Williams MA. Covid-19 and immunity in aging populations - A new research agenda. New Engl J Med. 2020; 383: 804-805.

2. World population prospects 2019. New York: United Nations; 2019. Available from: https://population.un.org/wwp/.

3. Bavishi C, Maddox TM, Messerli FH. Coronavirus disease (COVID-19) infection and renin angiotensin system blockers. JAMA Cardiol. 2020; 5: 745-747.

4. Pesheva E. Coronavirus and the heart. Health \& Medicine. Cambridge, MA: Harvard Gazette; 2020. Available from: https://news.harvard.edu/gazette/story/2020/04/covid-19sconsequences-for-the-heart/.

5. Eberli F. COVID-19 und das Herzgefäss-System. Erlenbach: Medinfo aerzteverlag; 2020. Available from: https://www.medinfo-verlag.ch/covid-19-und-das-herzgefaess-system/.

6. Poland GA, Ovsyannikova IG, Kennedy RB. Personalized vaccinology: A review. Vaccine. 2018; 36: 5350-5357.

7. Centers for disease Control and prevention. Antibiotic resistance threats in the United States, 2013. Atlanta, GA: US Department of Health and Human Services; 2015. Available from: https://www.cdc.gov/drugresistance/pdf/ar-threats-2013-508.pdf.

8. Presidential Advisory Council on Combating Antibiotic-Resistant bacteria: 2020-2025. A report with recommendations. Washington, D. C.: Assistant Secretary for Health; 2019. Available from:

https://www.hhs.gov/sites/default/files/PACCARB\%20NAP\%20Report\%20FINAL\%20Approved \%20by\%20Council.pdf.

9. Burnham JP, Olsen MA, Kollef MH. Re-estimating annual death due to multidrug-resistant organism infections. Infect Control Hosp Epidemiol. 2019; 40: 112-113.

10. McGlynn EA. Improving the quality of US Health Care - What will it take? New Engl J Med. 2020; 383: 801-803.

11. Cocco G. Bureaucracy and medicine, an unholy Marriage. Cardiovasc Med. 2012; 15: 243-244.

12. Cocco G. Physcians' dissatisfaction: A short review. Heart Mind. 2019; 2: 35-39. 


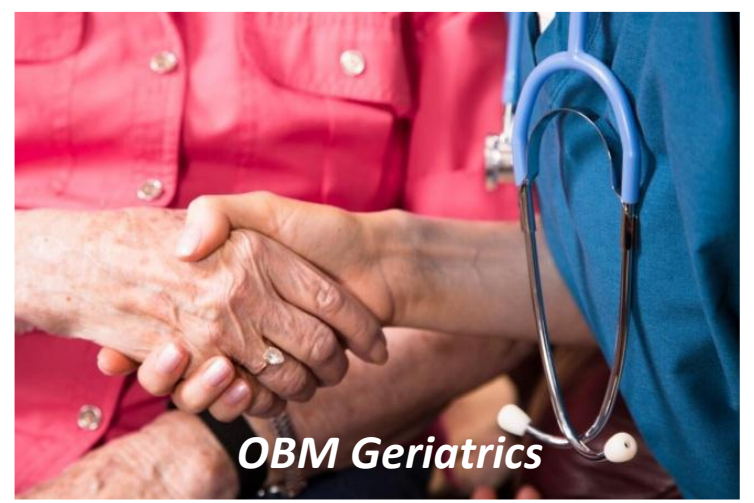

Enjoy $O B M$ Geriatrics by:

1. Submitting a manuscript

2. Joining in volunteer reviewer bank

3. Joining Editorial Board

4. Guest editing a special issue

For more details, please visit:

http://www.lidsen.com/journals/geriatrics 